\title{
Vitreon, a new perfluorocarbon
}

Kevin J Blinder, Gholam A Peyman, Christopher L Paris, James P Dailey, Walid Alturki, Kwan-Rong Lui, Charles M Gremillion Jr, Leland C Clark Jr investigational protocol approved by the institutional review board at the Louisiana State University in New Orleans. Of the 15 patients six presented with proliferative vitreoretinopathy (PVR) stages $\mathrm{C}_{2}-\mathrm{D}_{2}$, five with rhegmatogenous retinal detachment and peripheral tear; two with giant retinal tear; one with retinal dialysis; and one with tractional retinal detachment (Table 1). Nine patients $(60 \%)$ were male and six $(40 \%)$ female. The mean age was 48.5 years, range 28 to 79 years. Preoperative visual acuity ranged from 20/400 to light perception.

A standard 20-gauge three-port pars plana approach was used for vitrectomy. Once removal of the vitreous was completed, the decision to use Vitreon intraoperatively was made. The Vitreon was initially injected through a blunt 20 to 27 gauge needle over the optic disc. In the learning phase of the study it was discovered that a partial air-fluid exchange was necessary during the Vitreon injection process in order to tamponade the peripheral retina (Fig 1A, B, C). After a partial air-fluid exchange was performed, injection of Vitreon over the posterior pole was completed at a slow rate to allow displacement of the subretinal fluid anteriorly. In rhegmatogenous retinal detachments with peripheral breaks the subretinal fluid was forced from a posterior to an anterior direction out of the peripheral tear. The same procedure was used for giant retinal tears as well as with retinal dialyses with unfolding of the retinal flap.

In complicated PVR cases, after membrane peeling a small amount of Vitreon was injected to determine if the retina would flatten at this point. If traction was still evident, more dissection from a posterior-to-anterior direction was attempted. The other option consisted in performing varying degrees of retinotomies or retinectomies. At this point partial air-fluid exchange was performed to tamponade the peripheral intact retina or the remaining retinal skirt in the case of a $360^{\circ}$ retinectomy. The posterior vitreous cavity was then filled with Vitreon. Endolaser photocoagulation was then performed under Vitreon at the end of the operation when the retina was completely flat. An air-Vitreon exchange was then performed in all cases, with subsequent partial air-fluid exchange in an attempt to remove all the remaining Vitreon (Fig 1D, E). At this point a decision was made either to maintain the air inside the eye with subsequent $\mathrm{SF}_{6}(15-20 \%)$ or $\mathrm{C}_{3} \mathrm{~F}_{8}(10-15 \%)$ injection or to inject silicone oil for a longer tamponading effect. In eight eyes (53\%) intraocular gas was used; in six eyes $(40 \%)$ silicone oil (12 500 centistokes was used; and in one eye $(7 \%)$ fluorosilicone oil $(300 \mathrm{cSt}$ ) was used. A no 20 silicone band was then placed at the equator, and cryopexy was done at the sclerotomy sites.

Follow-up of the patients consisted in examin-
Correspondence to:

Gholam A Peyman, MD, LSU

Eye Center, 2020 Gravier

Street, Suite B, New Orleans,

Accepted for publication

22 October 1990
Rhegmatogenous retinal detachment

Giant retinal tea

Tractional retinal detachment

Total

15 

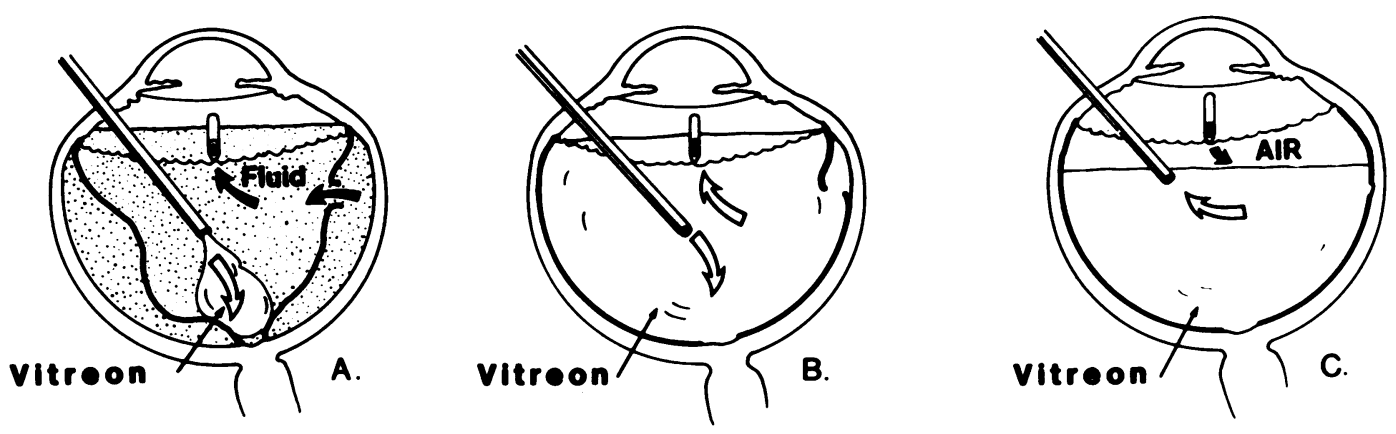

IMPLANTATION
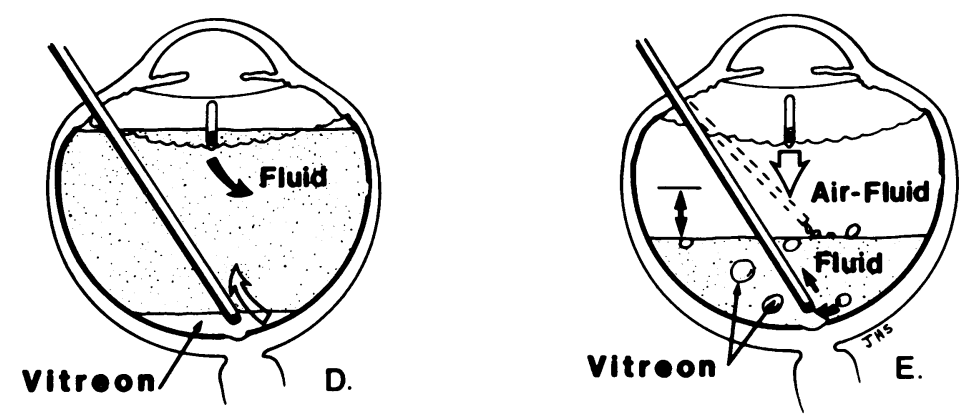

REMOVAL

Figure 1 Vitreon implantation ( $A$ and $B$ ) with partial air-fluid exchange during injection process $(C)$. Vitreon removal ( $D$ and $E$ ) with multiple fluid washings.

ations daily until stable, then weekly, bimonthly, and monthly for the first six months. Attention was directed to any excessive postoperative inflammation, cataract formation, intraocular pressure rise, membrane development, and retinal detachment. Any residual Vitreon noted in the eye postoperatively was removed by airfluid or fluid-fluid exchange at the slit-lamp. Those eyes with silicone oil complications such as keratopathy, cataract formation, or emulsification were treated by immediate oil removal. Recurrent retinal detachments were repaired with another operation.

\section{Results}

Vitreon was effective in flattening the retinas in all 15 cases intraoperatively. In four cases intraoperatively, after-removal of the Vitreon a redetachment occurred progressing from the periphery to the posterior pole. By careful examination we found that part of the subretinal fluid was trapped in the peripheral portion of the retina beyond the retinal tear. This situation necessitated a partial air-fluid exchange to the level of the retinal tear followed by further intravitreal injection of Vitreon. The peripheral air bubble flattened the anterior retina while the Vitreon reattached the posterior retina. No other intraoperative complications related to the use of Vitreon were experienced.

Table 2 shows the postoperative results of the 15 patients. No patients had any unusual inflammatory or toxic reaction related to the use of Vitreon. One patient experienced a postoperative rise in intraocular pressure most likely related to the use of intraocular gas. Five patients had residual intraocular Vitreon bubbles, which were subsequently removed at the slit-lamp. Future cases then required multiple air-fluid exchange to ensure complete removal of the Vitreon. None of the patients with residual Vitreon showed an increased inflammatory reaction or keratopathy related to the Vitreon. One patient had a vitreous haemorrhage postoperatively secondary to an underlying bleeding diathesis. The blood cleared spontaneously over a six to eight week period.

Two patients experienced recurrent retinal detachments secondary to PVR. Both patients underwent successful surgery with membrane peeling and reattachment of the retina. Two patients in the series developed hypotony postoperatively with intraocular pressure of less than $5 \mathrm{mmHg}$, and another developed significant macular pucker. Overall, the retina was finally reattached in all the patients, with a mean followup duration of 6.3 months and a range of four to nine months. Postoperative visual acuities were better than or equal to the preoperative visual acuities in all cases except for patient five, who developed PVR necessitating another operation (Table 2).

\section{Discussion}

Perfluorophenanthrene (Vitreon) contains inherent physical properties necessary for a 
Table 2 Postoperative results

\begin{tabular}{|c|c|c|c|c|c|c|c|}
\hline Case & $\begin{array}{l}\text { Age/Sex } \\
\text { (Years) }\end{array}$ & Nature $R d$ & $\begin{array}{l}\text { Preop. vis. } \\
\text { acuity }\end{array}$ & $\begin{array}{l}\text { Intraop. } \\
\text { complications }\end{array}$ & $\begin{array}{l}\text { Postop. } \\
\text { complications }\end{array}$ & $\begin{array}{l}\text { Follow-up } \\
\text { (months) }\end{array}$ & $\begin{array}{l}\text { Postop. vis. } \\
\text { acuity }\end{array}$ \\
\hline $\begin{array}{l}1 \\
2 \\
3\end{array}$ & $\begin{array}{l}50 \mathrm{M} \\
32 \mathrm{M} \\
68 \mathrm{~F}\end{array}$ & $\begin{array}{l}\text { Rhegmatogenous } \\
\text { RD with dialysis } \\
\text { Rhegmatogenous }\end{array}$ & $\begin{array}{l}\text { CF } \\
\text { CF } \\
20 / 400\end{array}$ & $\begin{array}{l}0 \\
0 \\
\text { Reinjection due to } \\
\quad \text { redetachment }\end{array}$ & $\begin{array}{l}\text { Residual Vitreon } \\
\text { Exotropia } \\
\text { Vitreous haemorrhage; } \\
\text { residual Vitreon; } \\
\text { Increased IOP }\end{array}$ & $\begin{array}{l}5 \\
9 \\
8\end{array}$ & $\begin{array}{l}20 / 60 \\
20 / 30 \\
20 / 200\end{array}$ \\
\hline 4 & $39 \mathrm{~F}$ & $\begin{array}{l}\text { Tractional with vitreous } \\
\text { haeme }\end{array}$ & HM & 0 & 0 & 8 & $20 / 200$ \\
\hline 5 & $48 M$ & $\begin{array}{l}\text { Rhegmatogenous with } \\
\text { choroidal detachment }\end{array}$ & HM & $\begin{array}{l}\text { Choroidal detachment; } \\
\text { reinjection due to } \\
\text { redetachment }\end{array}$ & $\begin{array}{l}\text { PVR with redetachment, } \\
\text { reoperation }\end{array}$ & 8 & LP \\
\hline 6 & $64 M$ & Rhegmatogenous & LP & 0 & $\begin{array}{l}\text { PVR with redetachment, } \\
\text { reoperation with } \\
\text { Vitreon }\end{array}$ & 7 & HM \\
\hline $\begin{array}{l}7 \\
8\end{array}$ & $\begin{array}{l}58 \mathrm{~F} \\
79 \mathrm{~F}\end{array}$ & $\begin{array}{l}\text { PVR } D_{2} \text { and Macular hole } \\
\text { PVR } D_{1}\end{array}$ & $\begin{array}{l}\text { CF } \\
\text { CF }\end{array}$ & $\begin{array}{l}\mathbf{0} \\
\mathbf{0}\end{array}$ & Hypotony & $\begin{array}{l}7 \\
4\end{array}$ & CF \\
\hline 9 & $33 \mathrm{M}$ & $\begin{array}{l}\text { Rhegmatogenous with } \\
\text { choroidal detachment }\end{array}$ & LP & $\begin{array}{l}\text { Reinjection of } \\
\text { fluorosilicone due to } \\
\text { redetachment }\end{array}$ & PVR & 5 & $20 / 70$ \\
\hline 10 & $28 \mathrm{M}$ & Giant tear & HM & 0 & 0 & 5 & $20 / 200$ \\
\hline 11 & $57 \mathrm{M}$ & Giant tear & $\mathrm{CF}$ & 0 & Cataract & 7 & $20 / 400$ \\
\hline 12 & $52 \mathrm{M}$ & PVR C $_{2}$ & LP & 0 & Residual Vitreon & 6 & $\mathrm{CF}$ \\
\hline 13 & $49 \mathrm{M}$ & PVR $D_{1}$ & LP & 0 & Residual Vitreon & 5 & CF \\
\hline 14 & $35 \mathrm{~F}$ & $\mathrm{PVRC}_{2}$ & $\mathrm{CF}$ & 0 & Residual Vitreon & 5 & $20 / 100$ \\
\hline 15 & $35 \mathrm{~F}$ & PVR C $_{3}$ & LP & 0 & Macular pucker & 5 & CF \\
\hline
\end{tabular}

$\mathrm{CF}=$ Counting fingers. $\mathrm{HM}=$ Hand motion. $\mathrm{IOP}=$ Intraocular pressure. $\mathrm{PVR}=$ Proliferative vitreoretinopathy. $\mathrm{LP}=\mathrm{Light}$ perception. $\mathrm{RD}=\mathrm{Retinal}$ detachment. $M=$ Male. $F=$ Female.

desirable denser-than-water temporary vitreous substitute. It has a specific gravity of 2.03 , a viscosity of $8.03 \mathrm{cSt}$, and a boiling point of $215^{\circ} \mathrm{C}$. It is immiscible with water, optically clear, and easily injected and removed through a small (20-27 gauge) needle. Past experimental studies with this substance have demonstrated no toxicity to culture-grown retinoblastoma cells. ${ }^{10}$ Vitreon was not toxic to the vitrectomised rabbit eyes when left in place for six weeks. No acute toxic or inflammatory reactions were noted during the operation or in the immediate postoperative period. In rabbit eyes fragmentation of the Vitreon into small globules in the vitreous cavity was noted at six weeks, which is later in onset than for previously studied liquid fluorocarbons.' Postoperative electroretinographic recordings revealed no pathological changes in eyes tested. Light and electron microscopy of rabbit eyes at the end of follow-up showed retention of normal retinal architecture with no evidence of retinal toxicity. Corneal toxicity was noted, however, on injection of Vitreon into the anterior chamber of rabbit eyes as evidenced by corneal oedema.

In the present study we used Vitreon to facilitate reattachment of the retina in a variety of complex vitreoretinal disorders. None of the eyes showed any adverse or toxic effects directly related to its use, either intraoperatively or postoperatively. Even the eyes with inadvertent small amounts of Vitreon in the anterior chamber postoperatively failed to show any corneal toxic effects.

Modifications in the injection and removal techniques were made as experience was gained during the progression of the study. A few of the earlier patients were noted postoperatively to have small amounts of Vitreon remaining intraocularly. As a result all subsequent cases underwent multiple air-fluid exchanges in order to achieve complete removal of the Vitreon. Also during the injection a unique problem was confronted early in the series. In patients with rhegmatogenous retinal detachments with peripheral tears or holes Vitreon was used to 'steamroll' the subretinal fluid from the posterior pole out through the anterior retinal tear. This was achieved simply by injecting the Vitreon over the optic disc and observing the flattening effect as the Vitreon level rose. However, on removal of the Vitreon redetachment occurred in some cases as the liquid fluorocarbon level decreased. In these cases subretinal fluid was pushed by Vitreon pressure in the periphery past the retinal tear, not escaping through the defect. On removal of the Vitreon the subretinal fluid simply shifted back to its posterior gravitydependent position. To avoid this complication in subsequent cases we performed a limited airfluid exchange prior to filling the vitreous cavity with the Vitreon, causing the air bubble to tamponade the retina anterior to the tear. Vitreon injection over the optic disc was continued, slowly displacing the subretinal fluid out through the peripheral break, but not allowing it to go anterior to this point. Once the retina was flat, endolaser and/or cryotherapy was applied, and the air-fluid exchange was completed with resultant complete reattachment of the retina.

The diversity of preoperative diagnoses in our series demonstrates the potential utility of Vitreon in vitreoretinal surgery. Five patients presented with rhegmatogenous retinal detachments with peripheral breaks. Vitreon was used as described above, thus avoiding a posterior retinotomy for internal drainage of subretinal fluid. This step bypassed the potential complications associated with posterior retinotomies, such as bleeding and reproliferation from the site of the retinotomy. ${ }^{11}$

Many different techniques have been proposed for management of giant retinal tears; liquid fluorocarbons are the most recent method to be investigated. ${ }^{12-14}$ Two patients in our study presented with giant retinal tears. Vitreon injection after vitrectomy greatly simplified the repair of these difficult cases. Injection was begun over the optic disc. Further injection resulted in the unfolding of the retina, hydrokinetically tamponading the retina back against the retinal pigment epithelium with the patient in a supine 
position. Posterior slippage of the retina was never encountered. Endolaser photocoagulation and/or retinal cryopexy was then performed as needed. Repair of retinal dialysis with detachment was accomplished in a similar fashion.

The diagnosis of proliferative vitreoretinopathy was encountered in six patients in our series, ranging from grade $C_{2}$ to $D_{2}$. Previous authors have reported the utility of liquid fluorocarbons in the management of PVR. ${ }^{15}$ Vitrectomy with intricate membranectomy was performed first. If the traction release from membranectomy was adequate, Vitreon was then injected with resultant good flattening of the retina. If some traction was still evident under Vitreon, further membranectomy was performed. Anterior loop traction was also considered in a few cases, with countertraction provided by the heavy vitreous substitute. In those patients with persistent traction, or initially severe PVR not amenable to membranectomy alone, relaxing retinotomies of varying degrees ranging from 180 to $360^{\circ}$ were performed. Vitreon was then injected over the retina for stabilisation of the retina and further membranectomy, if indicated.

The Vitreon was removed from all eyes intraoperatively through fluid-Vitreon or air-Vitreon exchange. Postoperative vitreous replacement was accomplished with gas in eight cases, silicone oil in six cases, and fluorosilicone oil in one case.

Study of heavier-than water vitreous replacement substances was first begun in 1962 by Cibis, with injection of fluorosilicone oil into rabbit eyes. ${ }^{12}$ Yet minimal interest was shown in this substance from the early 1960 s until the late $1980 \mathrm{~s}^{816-18}$ Other investigators have demonstrated the utility of fluorosilicone oil as a denserthan-water vitreous substitute. ${ }^{319-22}$ There are, however, major disadvantages in the use of this heavy oil versus Vitreon intraoperatively. The first is the lighter specific gravity of fluorosilicone oil, $1.31 \mathrm{~g}$ as compared to $2.03 \mathrm{~g}$ for Vitreon. This difference allows for a more efficient tamponading effect with Vitreon than with fluorosilicone. The other disadvantage is found when comparing the viscosity of the two substances. The viscosity of fluorosilicone oil ranges from 300 to $10000 \mathrm{cSt}$, thus greatly hampering both the injection and removal of this substance. Vitreon, with a viscosity of $8.03 \mathrm{cSt}$, is injected and removed from the eye as easily as balanced salt solution. This factor is important during intraoperative removal of the vitreous substitutes. Vitreon removal is accomplished easily by. passive flow.through a flute needle. The fluorosilicone oil, however, must be removed with an extrusion needle at high suction, which can be dangerous under air because of rapid swings of intraocular pressure when air is aspirated.

Previous studies of liquid fluorocarbons have been performed by various investigators. Miyamoto et al looked at two separate perfluoroether liquids, Freon E15 and Fomblin-H Fluorinated Fluid, finding both substances to be unsuitable vitreous substitutes owing to poor ocular tolerance of them. ${ }^{68}$ More recently Chang and associates ${ }^{9}$ studied perfluorotributylamine $\left(\mathrm{C}_{12} \mathrm{~F}_{27} \mathrm{~N}\right)$ in rabbit eyes and observed good intraoperative tolerance, but poor postoperative tolerance when left in the eye. They concluded the substance was a poor long-term vitreous substitute because of the dispersion, foam cell response, and photoreceptor toxicity if the retina was exposed to it for longer than two weeks. Chang $^{23}$ subsequently reported on the use of perfluorotributylamine and perfluorodecalin intraoperatively in four patients with good intraocular tolerance. In the management of traumatic retinal detachments Chang reported the intraoperative use of three liquid perfluorocarbons (perfluorotributylamine, perfluorodecalin, and perfluoroctane) in 14 patients. Of 11 eyes, with at least six months' follow-up, eight $(73 \%)$ had the retina anatomically reattached. ${ }^{24}$ Giant retinal tears have also been successfully treated by intraoperative liquid fluorocarbons. ${ }^{14}$

In all previous studies of liquid fluorocarbons the intraocular tolerance of them has been shown to be very poor when left in the eye postoperatively. ${ }^{69}$ The properties of the ideal denser-than-water vitreous substitute must also include an inert nature providing ample ocular tolerance. Investigation of Vitreon has proceeded in a step-wise fashion. The first investigation established good ocular tolerance in rabbit eyes for up to six weeks. ${ }^{10}$ The next phase of study is presented here, with the establishment of good ocular tolerance in human eyes intraoperatively. The next step in the order of progression will be to leave the Vitreon in human eyes postoperatively until the formation of a firm chorioretinal scar. Thus Vitreon would provide a short-term tamponading effect that is occasionally desirable in complicated cases. We are now evaluating this phase of the study.

This work was supported in part by US Public Health Service This work was supported in part by US Public Health Service National Institutes of Health Services, Bethesda, MD.

The Vitreon was donated by Vitrophage Inc, Downer's Grove, IL, USA.

1 Cibis PA, Becker B, Okun E, Canaan S. The use of liquid silicone in retinal detachment surgery. Arch Ophthalmol 1962; 68: 590-9.

2 Cibis PA. Vitreous transfer and silicone injections. Ophthalmology 1964; 68: 983-97.

3 Peyman GA, Smith RT. Use of fluorosilicone to unfold a giant retinal tear. Int Ophthalmol 1987; 10: 149-51.

4 Clark LC Jr, Gollan F. Survival of mammals breathing organic fluids equilibrated with oxygen at atmospheric pressure. Science 1966; 152: 1755-6.

5 Haidt SJ, Clark LC, Ginsberg J. Liquid perfluorocarbon replacement of the eye. Invest Ophthalmol Vis Sci 1982; 22 (suppl): 233.

6 Miyamoto K, Refojo MF, Tolentino FI, Fournier GA, Albert DM. Perfluoroether liquid as a long-term vitreous substitute: an experimental study. Retina $1984 ; 4: 264-8$.

7 Zimmerman NJ, Faris D. The use of N-perfluorocarbon amines in complicated retinal detachments. Invest Ophthalmol Vis Sci 1984; 25 (suppl): 258.

8 Miyamoto K, Refojo MF, Tolentino FI, Fournier GA, Albert DM. Fluorinated oils as experimental vitreous substitutes. Arch Ophthalmol 1986; 104: 1053-6.

9 Chang S, Zimmermann NJ, Iwamoto T, Ortiz R, Faris D. Experimental vitreous replacement with perfluorotributylamine. Am f Ophthalmol 1987; 103: 29-37.

10 Nabih M, Peyman GA, Clark LC, et al. Experimental evaluation of perfluorophenanthrene as a high specific gravity vitreous substitute: a preliminary report. Ophthalmic Surg 1989; 20: 286-93.

11 Machemer R, McCuen BW II, de Juan E Jr. Relaxing retinotomies and retinectomies. Am $\mathcal{F}$ Ophthalmol 1986; 102: 7-12.

12 Machemer R, Allen AW. Retinal tears $180^{\circ}$ and greater: management with vitrectomy and intravitreal gas. Arch Ophthalmol 1976; 94: 1340-6.

13 Peyman GA, Schulman JA. Intravitreal surgery: principles and practices. Norwalk, Connecticut: Appelton-Century-Crofts, 1986: 294-303. 
14 Chang S, Lincoff H, Zimmerman NJ, Fuchs W. Giant retinal tears: surgical techniques and results using perfluorocarbon liquids. Arch Ophthalmol 1989; 107: 761-6.

15 Chang S, Ozmert E, Zimmerman NJ. Intraoperative perfluorocarbon liquids in the management of proliferative vitreoretinopathy. Am f Ophthalmol 1988; 106: 668-74.

16 Watzke RC. Silicone retinopiesis for retinal detachment: a long-term clinical evaluation. Arch Ophthalmol 1967; 77: 185-196.

17 Moreau PG. Les silicones intra-oculaires dans les décollements de rétine désespérés. Ann Oculist (Paris) 1967; 200: 257-65.

18 Labelle P, Okun E. Ocular tolerance to liquid silicone: an experimental study. Can f Ophthalmol 1972; 7: 199-204.

19 Paylor R, Peyman GA, Badri S. Effects of intravitreal injection of fluorosilicone oil after vitrectomy in the rabbit eye. $\operatorname{Can} \mathcal{F}$ Ophthalmol 1987; 22: 251-3.
20 Peyman GA, Smith RT, Charles H. Injection of fluorosilicone oil and pars plana vitrectomy for complex retinal detachment. Can f Ophthalmol 1987; 22: 276-8.

21 Liu KR, Peyman GA, Miceli MV. Experimental evaluation of low-viscosity fluorosilicone oil as temporary vitreous substitute. Ophthalmic Surg 1989; 20: 720-5.

22 Gremillion CM, Peyman GA, Liu KR, Naguib KS. Fluorosilicone oil in the treatment of retinal detachment. $\mathrm{Br} F$ Ophthalmol 1990; 74: 643-6.

23 Chang S. Low viscosity liquid fluorochemicals in vitreous surgery. Am 7 Ophthalmol 1987; 103: 38-43.

24 Chang S, Reppucci V, Zimmerman NJ, Heinemann MH, Coleman DJ. Perfluorocarbon liquids in the management of traumatic retinal detachments. Ophthalmology 1989; 96: 785-92. 